\title{
ASSOCIATION BETWEEN DECREASES IN TYPE V COLLAGEN AND APOPTOSIS IN MOUSE LUNG CHEMICAL CARCINOGENESIS: A PRELIMINARY MODEL TO STUDY CANCER CELL BEHAVIOR
}

\author{
Edwin Roger Parra, ${ }^{\mathrm{I}}$ Leonardo Cavallari Bielecki, ${ }^{\mathrm{I}}$ José Mauro da Fonseca Pestana Ribeiro, ${ }^{\mathrm{I}}$ Fernando de Andrade Balsalobre, ${ }^{\mathrm{I}}$ \\ Walcy R. Teodoro, "I Vera Luiza Capelozzi ${ }^{I}$
}

doi: $10.1590 / \mathrm{S} 1807-59322010000400012$

Parra ER, Bielecki LC, Ribeiro JMFP, Balsalobre FA, Teodoro WR, Capelozzi VL. Association between decreases in type $\mathrm{V}$ collagen and decreases and apoptosis lessening in the mouse lung chemical carcinogenesis: a preliminary model to study cancer cell behavior. Clinics. 2010;65(4): 425-32.

OBJECTIVE: The importance of type V collagen and its relationships with other types of collagen and with vascular and epithelial apoptosis were studied in a model of chemical carcinogenesis in the mouse lung.

METHODS: Two groups of male Balb/c mice were studied: a) animals that received two intraperitoneal doses of $3 \mathrm{~g} / \mathrm{kg}$ urethane carcinogen (urethane group $=24$ ); and b) animals submitted to a sham procedure, comparable to the test group (control group = 7). Both groups were sacrificed after 120 days. In situ detection of apoptosis, immunohistochemistry, immunofluorescence and histomorphometry were used to evaluate the fraction occupied by the tumor, vascular and epithelial apoptosis, and type V, III and I collagen fibers in the lung parenchyma from both groups.

RESULTS: The lung parenchyma from the urethane group showed low fractions of vascular and epithelial apoptosis as well as reduced type $\mathrm{V}$ collagen fibers when compared to the control group. A significant direct association was found between type $\mathrm{V}$ and III collagen fibers and epithelial apoptosis, type V collagen fibers and vascular apoptosis, and type V and type I collagen fibers.

CONCLUSION: The results show that a direct link between low amounts of type $\mathrm{V}$ collagen and decreased cell apoptosis may favor cancer cell growth in the mouse lung after chemical carcinogenesis, suggesting that strategies aimed at preventing decreased type $\mathrm{V}$ collagen synthesis or local responses to reduced apoptosis may have a greater impact in lung cancer control.

KEYWORDS: Experimental lung cancer; Imunohistochemistry; Immunofluorescence; Type V collagen; Morphometry.

\section{INTRODUCTION}

Despite advances in surgery, chemotherapy, and radiotherapy over the previous two decades, the death rate for lung cancer remains mostly unchanged, and the main cause of this is metastasis. ${ }^{1}$ Thus, there is great interest in methods for identifying tumors that are likely to invade, metastasize and shorten patient life in order to optimize the therapeutic

\footnotetext{
${ }^{I}$ Departament of Pathology, Faculdade de Medicina da Universidade de São Paulo - Sao Paulo/SP, Brazil.

II Discipline of Rheumatology, Faculdade de Medicina da Universidade de São Paulo - São Paulo/SP, Brazil.

Emails: erparra20003@yahoo.com.br / vcapelozzi@lim05.fm.usp.br Tel.: 55113061.7427

Received for publication on November 25, 2009

First review completed on December 17, 2009

Accepted for publication on December 23, 2009
}

effort for each individual patient. In this regard, our group has been studying morphometric and biological markers in resected lung cancer and its corresponding lymphatic and hematogenous metastatic tissue. ${ }^{2-12}$ Because lung cancer is the phenotypic consequence of interactions between cellular and microenvironmental factors (such as blood supply and the extracellular matrix) for growth, invasion and metastasis, much interest is currently focused on the influence of these factors on programmed cell death, or apoptosis.

The extracellular matrix (ECM) contains a significant number of "informational" molecules whose interaction with scattered cells is of primary importance in the control of cellular proliferation and differentiation in cancer development. ${ }^{13}$ One of the most common features of the majority of highly invasive tumors, such as lung cancer, is massive degradation of the basement membrane. ${ }^{14}$ 
Additionally, remarkable qualitative and quantitative modifications of the interstitial collagen component have been described. ${ }^{14-16}$ Type $\mathrm{V}$ collagen is a component of the ECM that is located in the pulmonary interstitium and capillary basement membranes, and surrounded by vascular smooth muscle cells. ${ }^{17}$ It is a highly conserved protein found with the same $\mathrm{NH}_{2}$ terminal end in many animal species, making it more immunogenic. ${ }^{18}$ Normally, this protein is not exposed in the ECM, as it is hidden among type I and III collagens as a component of heterotypic fibers. ${ }^{19}$ Type V collagen, a "minor" component accounting for approximately $1 \%$ of the total collagen in normal breast stroma, was found to be over-deposited in the ECM of breast carcinoma, comprising up to $10 \%$ of extractable collagens. ${ }^{20}$ Subsequently, "in vitro" experiments using breast cancer ${ }^{21}$ demonstrated the direct binding of type $\mathrm{V}$ collagen epitopes to a non-integrin receptor recognized by an anti-elastin/ laminin-binding protein antibody, resulting in a prominent retardation of the growth rate and an inhibition of motility and invasion. ${ }^{22}$ More recent results provided evidence that type $\mathrm{V}$ collagen could trigger apoptosis via caspase 9 in breast cancer tissue. ${ }^{20}$

In light of these previous data suggesting an effect of type $\mathrm{V}$ collagen on growth inhibition and cell death rate, the aim of the present study was to evaluate type $\mathrm{V}$ collagen, the relationship between type $\mathrm{V}$ collagen and other collagen types, and epithelial and vascular apoptosis in the lung parenchyma of mice modified by chemical carcinogenesis.

\section{MATERIALS AND METHODS}

\section{Chemical carcinogenesis model}

The experiments to induce chemical carcinogenesis in the mouse lung followed the guidelines of the National Institutes of Health, after receiving approval from the Institutional Review Board for animal experiments.

Twenty-four male Balb/c mice were treated with $3 \mathrm{~g} /$ $\mathrm{kg}$ body weight of urethane provided by the pharmacy of our teaching hospital. The drug was administered in two intraperitoneal injections of $1.5 \mathrm{~g} / \mathrm{kg}$, with a 48 hr interval. A previous study showing this dose to be the highest concentration that did not elicit massive mortality immediately after injection and that promoted the development of identifiable pulmonary nodules within a time span of 48 days. ${ }^{23-24}$ Seven animals were submitted to a sham procedure was comparable to that in the test group. Animals were randomly assigned to the urethane or control groups. After 120 days of lung tumorigenesis induced by urethane that resulted in fully developed tumors, ${ }^{23}$ 24 animals from the urethane group and seven from the control group were sacrificed. The animals were sedated, anesthetized with $20 \mathrm{mg} / \mathrm{kg}$ intraperitoneal pentobarbital sodium and exsanguinated by sectioning the caudal aorta. The lungs were rapidly removed, dissected, rinsed free of blood with saline solution, inflated in situ through the trachea at a pressure of $15 \mathrm{mmH}_{2} \mathrm{O}$, measured with respect to tidal volume and fixed with $10 \mathrm{ml} / \mathrm{kg}(0.2 \mathrm{ml})$ of buffered formalin for six hours. Then, the lungs were kept in $70 \%$ ethanol for $24 \mathrm{hrs}$ at ambient temperature to complete tissue fixation. The mediastinal lymph nodes and abdominal organs were also examined macroscopically for the presence of tumors. Four animals from the urethane group exhibited two to three tumors measuring from 3 to $5 \mathrm{~mm}$ in the lymph nodes. No tumors were observed in the abdominal organs. After fixation, tumors in each lung from both groups of animals were investigated by examining the pleural and the cut surface of sagittal sections of the lung parenchyma. All animals from the urethane group presented three to five tumors measuring from 5 to $10 \mathrm{~mm}$ that were randomly scattered in all pulmonary lobes. A routine histological procedure was done, and the paraffin-embedded specimens were sectioned at $5 \mathrm{~m}$. Each section contained the whole cross-sectional area of the lung of each mouse. Lung sections were stained with hematoxylin-eosin for tumor characterization. Immunostaining for caspase 9 expression and end-labeling (TUNEL) were used for in situ apoptosis detection. Type I, III and V collagen were detected by immunofluorescence.

\section{Animal tumor characterization}

The tumors were submitted to qualitative and quantitative histopathological analysis. They were classified according to pathological criteria proposed by Kauffman ${ }^{25}$ and Ward. ${ }^{26}$ Two pathologists (ERP and VLC) who were blinded as to the group assignment performed the classification. All of the tumors from the urethane group were histologically characterized as invasive adenocarcinoma with acinar and papillary mixed pattern, and the criteria included acini, tubules and papillae composed of atypical cuboidal or columnar cells invading a loose and uniform desmoplastic stroma and replacing the underlying lung architecture (Figure 1B). Similar findings were found in metastatic adenocarcinoma in the lymph nodes (detail in Figure 1B).

\section{Caspase 9 immunostaining}

Caspase 9 immunostaining was performed to identify apoptosis in the vascular endothelium of lungs from the urethane and control groups using an antibody purchased from Chemicon (Temecula, Ca, USA, dilution: 1:6000) that 

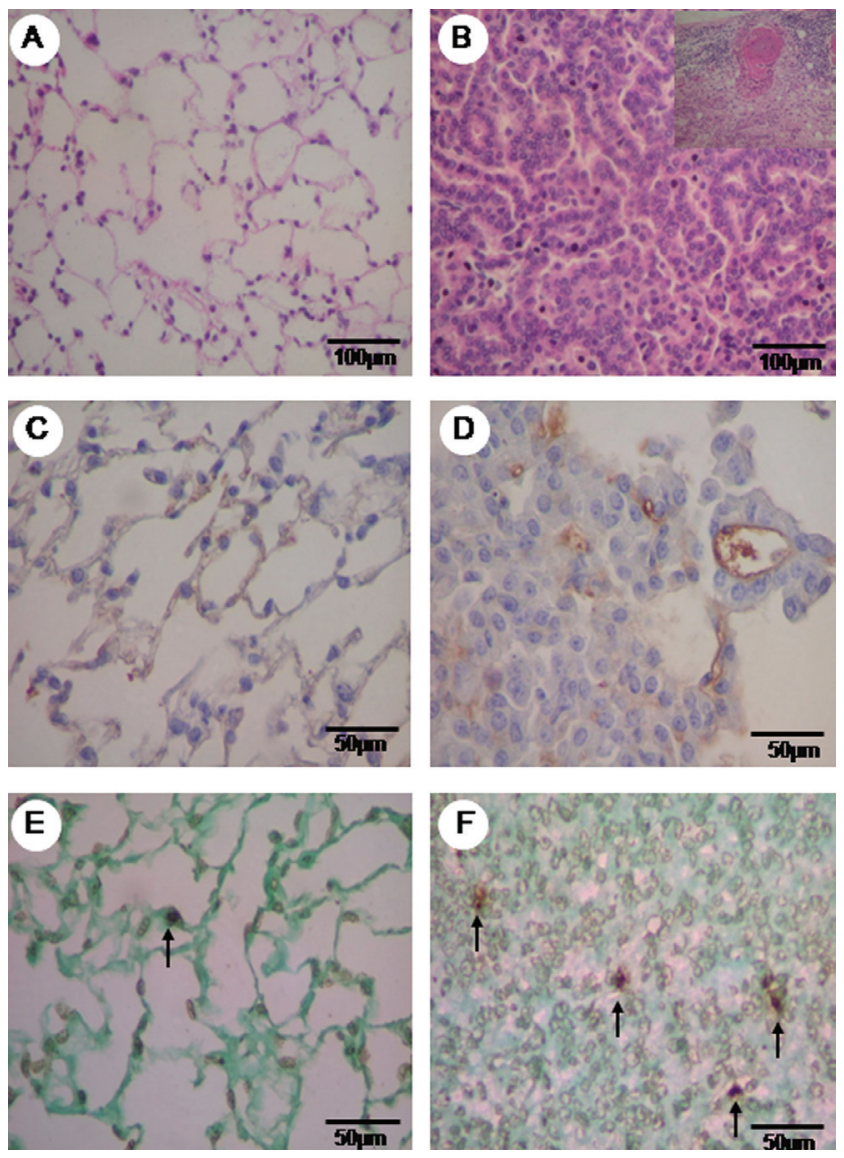

Figure 1 - Hematoxylin eosin (HE) staining of normal parenchyma of the control group (A) and the urethane group, with an adenocarcinogenic area and the detail of the adenocarcinogenic metastasis of the lymph node (B). Vascular caspase 9 is minimally immunolabeled in the control group (C) and shows major expression in the tumor parenchyma (D). Minimal TUNEL $(+)$ staining is observed in the normal area (E) of the control group TUNEL staining is increased in the tumor parenchyma (F). HE in A,B is at 200x, immunohistochemistry for caspase 9 in C,D is at 400x and TUNEL (+) apoptosis in $\mathrm{E}, \mathrm{F}$ is at 400x magnification.

is specific for the cleaved form of caspase 9. The Novolink Max Polymer (Novocastra Laboratories LTDA), pressurecooking antigen retrieval, biotinylated rabbit antimouse IgG (Dako Corp; dilution. 1:400), and streptavidin were used in combination with biotinylated horseradish peroxidase (Dako Corp.; dilution 1:1000), diaminobenzidine tetrahydrochloride, and counterstaining with hematoxylin. Brownish cytoplasmic staining was considered evidence of antigen expression by the cells.

\section{In situ apoptosis detection}

Apoptosis in lung epithelial cells from the urethane and control groups was detected by the deoxynucleotidyl transferase (TdT) method of end-labeling (TUNEL) (Boehringer Mannheim, Mannheim, Germany). ${ }^{27-28}$ This method involves the addition of deoxyuridine triphosphate (dUTP) labeled with fluorescein to the ends of the DNA fragments by the catalytic action of TdT. Paraffin waxembedded sections $(3-4 \mu \mathrm{m})$ were layered onto glass slides. The tissue sections were dewaxed with xylene and rehydrated with graded dilutions of ethanol in water. The slides were then washed four times with double-distilled water for two minutes and immersed in TdT buffer (Boehringer Mannheim). The sections were then covered with $\mathrm{TdT}(0.3 \mathrm{U} / \mu \mathrm{l})$ and fluorescein-labeled dUTP in TdT buffer, and the samples were incubated in a humid atmosphere at $37^{\circ} \mathrm{C}$ for 60 minutes. For negative controls, TdT was eliminated from the reaction mixture. The sections were then incubated with a peroxidase-conjugated antibody specific for fluorescein. The staining was observed with a substrate system in which nuclei with DNA fragmentation were stained brown. The reaction was terminated by washing the sections twice in phosphate-buffered saline. Nuclei without DNA fragmentation were stained blue as a result of counterstaining with hematoxylin.

\section{Immunofluorescence detection of type I, III and V collagens}

Type I, III, and V collagens in lung ECM from the urethane and control groups were detected in sections mounted on gamma methacryloxypropyltrimethoxysil ane-coated (Sigma Chemical Co.) slides. The sections were dewaxed in xylene and dehydrated in graded ethanol. Antigen retrieval was done by enzymatic treatment of lung sections with bovine pepsin (10000 UTD) (Sigma Chemical Co.) in acetic acid buffer $(\mathrm{pH}=2.2)(4 \mathrm{mg} / \mathrm{ml})$ for $30 \mathrm{~min}$ at $37^{\circ} \mathrm{C}$. Subsequent incubation with $5 \%$ milk in phosphate buffer $\mathrm{pH}=7.0$ was performed to block the unspecific sites. The slides were then incubated overnight with rabbit polyclonal type I (1:100, collagen I from calf skin; Sigma Chemical Co., Saint Louis, MO, USA) and V (1:2000, collagen V from human placenta; Sigma Chemical Co., Saint Louis, MO, USA ), raised in our laboratory according to previous works of Miller and colleagues ${ }^{29}$ and Lane ${ }^{30}$, as well as monoclonal type III collagen (1:100) antibodies (Calbiochem, Bioscience Inc. CA). For negative controls, sections were incubated with fetal bovine serum instead of the primary antibody. The sections were incubated overnight at $4^{\circ} \mathrm{C}$ in a humid atmosphere with the same primary antibody diluted with phosphate-buffered saline (PBS) plus $1 \%$ bovine serum albumin (BSA). After the sections were incubated with FITC-conjugated goat anti-rabbit immunoglobulins (Sigma Chemical Co., Saint Louis, MO, USA; dilution 1:50) diluted in Evans blue 0,006\% in PBS during $90 \mathrm{~min}$ at room temperature. Finally, the section were mounted in glicine buffer and analyzed in a fluorescence microscopy (Olympus BX 51). 


\section{Histomorphometry}

The area fraction occupied by the tumor in the lung parenchyma and the apoptotic fraction of epithelial and endothelial cells in lungs from the urethane and control groups were evaluated by stereology. At 400x magnification, an eyepiece systematic point-sampling grid with 100 points and 50 lines was used to count the number of points overlying positively-stained structures in the nuclei and endothelium, respectively. ${ }^{31}$ To evaluate tumor growth, the same procedure was applied to count the number of points overlying tumors from the urethane group. Measurements were averaged over ten microscopic fields to obtain the apoptotic and tumor growth index percentages.

Comparisons were performed in $20 \%$ of the slides by two observers (ERP and VLC). The coefficient of variation for the inter-observer error regarding cell count was $<5 \%$.

Type I, III, and V collagen fibers were quantified in the lung ECM from the urethane and control groups by image analysis. Briefly, an image analysis system consisting of an Olympus camera mounted on an Olympus microscope sent the images to an LG monitor by means of a computercontrolled (Pentium 1330Mhz) digitizing system (Oculus TCX, Coreco Inc., St. Laurent, Quebec, Canada). Images were processed by ImagePro-Plus 6.0 software (Media Cybernetics, Inc., Bethesda, MD, USA). For each lung specimen, the ECM compartment in the urethane group and ten normal samples of ECM from control groups were analyzed at a magnification of 400x. The collagen fiber densities in this compartment were expressed as the amount of fibers divided by the total area studied. The final results are expressed as the number of collagen fibers per total area. $^{31}$

\section{Statistical analysis}

The independent t-test was used for analysis of the density of collagen fibers and the apoptotic index in the two categories. Associations between variables in the TP were analyzed using the Spearman test. The level of significance was established as $\mathrm{p}<0.05$. The data were analyzed using the SPSS for Windows software (SPSS, Inc., Chicago, IL, USA), release 10.0.

\section{RESULTS}

Lung parenchyma from the control and urethane groups is shown in Figures 1 and 2 as stained by hematoxylin-eosin (1A and $1 \mathrm{~B}$, detail of adenocarcinoma metastasis to lymph node in 1B) and immunostained for vascular apoptosis (1C and 1D), epithelial apoptosis (1E and $1 \mathrm{~F})$, and type $\mathrm{V}$
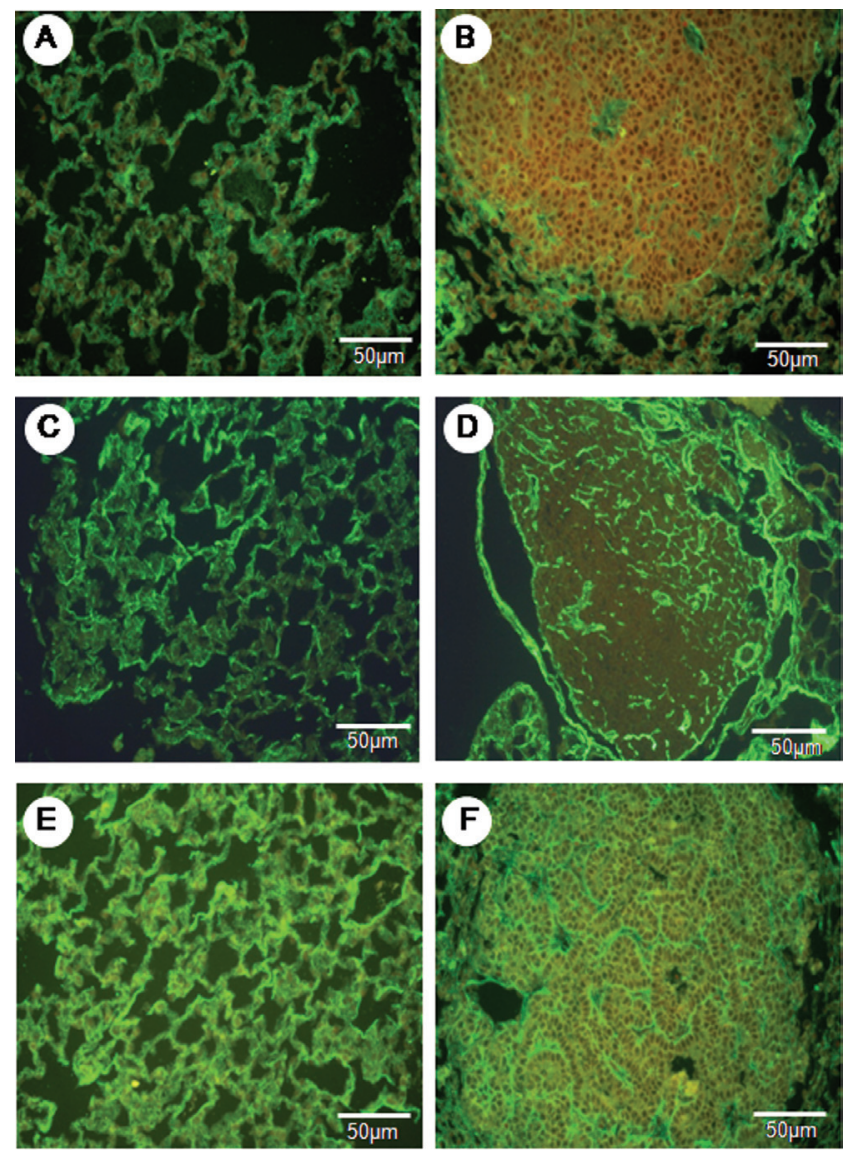

Figure 2 - The normal parenchyma in the lungs of the control animals shows a strong green birefringence of collagen V fibers (A). In contrast, the tumor parenchyma (B) shows a diffuse, green birefringence of collagen $\mathrm{V}$ fibers, which are organized in a reticular texture consisting of thin fibers that individually involve tumor cells and complex glands. The collagen III fibers show moderate green birefringence in the normal parenchyma $(C)$ when compared to the tumor parenchyma (D). A strong green birefringence in the normal parenchyma $(\mathrm{E})$ and tumor parenchyma $(\mathrm{F})$ is shown by collagen I fibers. Immunofluorescence in $\mathrm{A}$ to $\mathrm{F}$ is at $400 \mathrm{x}$ magnification.

( $2 \mathrm{~A}$ and $2 \mathrm{~B})$, type I (2C and $2 \mathrm{D})$ and type III (2E and $2 \mathrm{~F})$ collagens.

A preserved lung parenchyma sample from the control group and an invasive adenocarcinoma from the urethane group are shown, respectively, in Figures 1A and 1B. Lung parenchyma from the control and urethane groups showed scattered vessels and apoptotic epithelial cells (Figure 1C-E and Figure 1B-F). A similar green birefringence was found for type $\mathrm{V}$ and III collagen fibers in the ECM from the lung parenchyma of both groups (Figure 2A,B, E, F). Type I collagen showed slightly more green birefringence at the edge of the tumors, coincident with the more prominent desmoplastic reaction at this location (Figure 2C).

The histomorphometric results obtained from the measurements of the tumor, vascular and epithelial apoptotic areas in the lung parenchyma of the control and urethane groups are shown in Table 1.

Invasive adenocarcinoma occupied $7.87 \%$ of the 
Table 1 - Summary of morphometric results ${ }^{\mathrm{a}}$

\begin{tabular}{lcccc}
\hline Variable & Group & Mean & Minimum & Maximum \\
\hline Tumor area (\%) & Urethane & 7.87 & 1.66 & 26.56 \\
Vascular apoptosis (\%) & Urethane & 3.45 & 0.00 & 8.96 \\
& Control & 2.19 & 0.00 & 7.66 \\
Epithelial apoptosis (\%) & Urethane & 2.05 & 0.70 & 3.90 \\
& Control & 0.48 & 0.00 & 2.06 \\
Type V collagen (\%) & Urethane & $7.01 *$ & 0.00 & 12.35 \\
& Control & 16.33 & 5.75 & 36.79 \\
Type III collagen (\%) & Urethane & 24.62 & 0.00 & 50.87 \\
Type I collagen $(\%)$ & Control & 33.45 & 10.73 & 51.68 \\
& Urethane & 25.66 & 35.42 & 61.78 \\
\end{tabular}

aThe units "\% of points" indicate the number of points overlying the structure of interest divided by the total number of points overlying the tumor. In morphometry, this is called a point fraction and is often symbolized as Pp. Pp has been shown to approximate the volume fraction or Vv (30).

*Significantly different from the control $(\mathrm{p}<0.05)$.

lung parenchyma. Similar fractions of vascular and epithelial apoptosis were detected in lung parenchyma from the urethane and control groups. Type $\mathrm{V}$ collagen was significantly decreased in lung ECM from the urethane group compared to the control group $(7.01 \%$ vs. $16.33 \%$, $\mathrm{p}=0.002$ ). Type I and III collagen fiber fractions were similar in the lung ECM from the urethane and control groups (Figure 3).

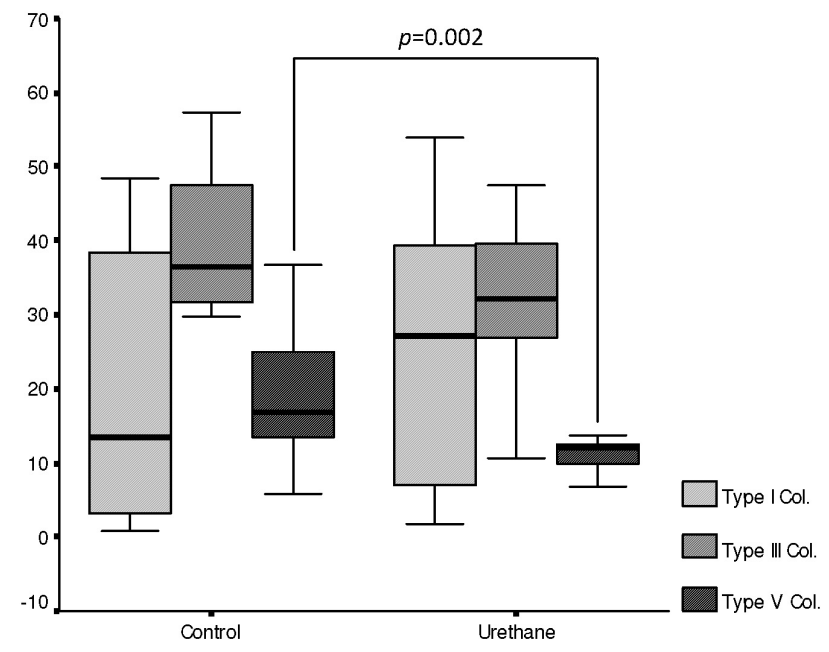

Figure 3 - Box plots showing the associations among collagen I, III and V between the control and urethane groups.

A significant direct association was found between type $\mathrm{V}$ and III collagen fibers and epithelial apoptosis $(\mathrm{R}=0.59, \mathrm{p}=0.05 ; \mathrm{R}=0.68, \mathrm{p}=0.02)$. Equally significant was the association between type $\mathrm{V}$ collagen fibers and vascular apoptosis $(\mathrm{R}=7.33, \mathrm{p}=0.01)$. No association was found between type I collagen fibers and vascular apoptosis $(\mathrm{R}=0.28, \mathrm{p}=0.4)$. Type $\mathrm{V}$ collagen fibers were significantly associated with type I collagen fibers $(\mathrm{R}=0.61, \mathrm{p}=0.05)$ and type III collagen fibers $(\mathrm{R}=0.72, \mathrm{p}=0.01)$.

\section{DISCUSSION}

A direct link may exist between decreased type $\mathrm{V}$ collagen fibers and reduced rate of cell death; such a link may favor cancer cell growth in the mouse lung after chemical carcinogenesis. Cancer cell growth comprises a series of complex, sequential steps. Among these, the quantitative modifications of cell apoptosis and changes in the interstitial collagen component of the ECM by either tumor cells or endothelial cells are thought to be important because they facilitate the adhesion and migration of tumor cells and the penetration of the tumor by blood vessels.

The structural and molecular features of type $\mathrm{V}$ collagen have been described extensively over more than a decade, ${ }^{32}$ but the biological role of this "minor" component of the ECM and the effect of its interactions with different cytotypes are still poorly understood. In previous studies, our group showed that rabbits immunized with human type $\mathrm{V}$ collagen, in an attempt to produce the corresponding antibodies, developed fibrosis due to collagen deposition in vessels and lung parenchyma. ${ }^{33-35}$ Our group also demonstrated prominent fibroblastic cell proliferation associated with increased type $\mathrm{V}$ collagen deposition in humans. ${ }^{36-38}$ From a review of the literature, a generic and unique role played by type $\mathrm{V}$ collagen seems unlikely because multiple, and sometimes opposite, cellular responses are evoked by this collagen substrate, depending upon the cell examined. In fact, type $\mathrm{V}$ collagen has been proven to represent an optimal substrate for the attachment and growth of hepatocytes, ${ }^{39}$ Schwann cells, ${ }^{40}$ normal smooth muscle 
cells, ${ }^{41}$ and some tumor cell types. ${ }^{42}$ Conversely, an antiadhesive and anti-proliferative role of this collagen species in neurons, ${ }^{40}$ various epithelial and endothelial cell lines, ${ }^{43}$ and breast cancer cell ${ }^{20}$ has also been described.

It should therefore not be surprising to learn that immunofluorescence staining for type $\mathrm{V}$ collagen provides important information about the attachment and growth of tumor cells, and our results now confirm the importance of type $\mathrm{V}$ collagen in chemically induced carcinogenesis in the mouse lung. Interestingly, our results suggest that a decrease in type $\mathrm{V}$ collagen fibers is associated with decreased apoptosis in epithelial cells and vessels induced by nuclear and mitochrondrial mechanisms, respectively, thus suggesting that decreased binding of type $\mathrm{V}$ collagen to epitopes on endothelial cells decreases the synthesis of type $\mathrm{V}$ collagen by fibroblasts and myofibroblasts and results in a reduced desmoplastic stroma reaction in tumors. Furthermore, endothelial apoptosis can provoke basement membrane injury and exposure of hidden type $\mathrm{V}$ collagen epitopes, generating new antigens that will trigger an immune response with the production of fibrogenic cytokines. In fact, it has been shown that type $\mathrm{V}$ collagen and immune cells may play a role in initiating and perpetuating inflammatory and fibrotic responses. ${ }^{44}$ Luparello ${ }^{20}$ demonstrated that an increase in type $\mathrm{V}$ collagen impairs the survival of breast cancer cells by promoting a caspase-dependent apoptotic type of death. Also reported to occur was the upregulation of the apoptotic initiator caspases 8 and 9, the apoptosis-involved caspase 1, and the related caspases 5 and 4, as well as a similar increase in the activity of some enzyme products. ${ }^{20}$ Caspases, which are the actual cause of death, are responsible for much of the proteolysis occurring during apoptosis, and their targets are factors involved in the repair, fragmentation, and duplication of DNA, in RNA splicing, in the maintenance of cytoskeletal integrity, and in cell division. ${ }^{45}$ In addition to endogenous events, such as genomic DNA damage, various extracellular ligands (e.g., TNF $\alpha$, Fas ligand, CD4, CD8, type V collagen) have been described to trigger apoptotic cell death or to exert an inhibitory effect (e.g., IGF-1 and GM-CSF). ${ }^{46}$ Thus, the density of type $\mathrm{V}$ collagen fibers and the apoptotic fraction in cells and vessels offer the potential to control tumor growth rate, motility and invasion, suggesting that strategies aimed at preventing reduced type $\mathrm{V}$ collagen synthesis or local responses to reduced cellular apoptosis may have a greater impact in lung cancer. The finalization of this conclusion will require more studies that validate our quantitative assessment of type $\mathrm{V}$ collagen and apoptosis, as well as the gathering of more information at the gene expression level.

The decreased density of type $\mathrm{V}$ collagen fibers in the ECM of the urethane group was associated with a decrease in other collagen fibers, such as I and III. The quantitative difference between the three types of collagen was also noticeable; type $\mathrm{V}$ collagen was found in a lower proportion in the ECM than types I and III. These findings are interesting because type I and III collagens are both usually upregulated in any type of lung remodeling. In the normal lung, small amounts of type $\mathrm{V}$ collagen are expressed as very thin fibrils in the basement membrane. These fibrils contribute to the binding between stromal collagen and the basement membrane, which is important for cell adhesion and the matrix repair process. ${ }^{17}$ Previous studies demonstrated that type $\mathrm{V}$ collagen co-polymerizes with type I and III collagens to produce fibrils with smaller diameters, thus resulting in a heterotypic assembly as a general regulatory mechanism in the control of fibril structure and collagen fibrillogenesis. ${ }^{17,32-38}$ In the current study, the noticeably decreased amount of type $\mathrm{V}$ collagen and consequently decreased co-polymerization with type I and III collagens may have facilitated invasion and motility and decreased the desmoplastic stroma reaction, without affecting the tumor center and the invasion front of the tumor. In fact, an inverse correlation between the extent of the desmoplastic stroma reaction and the progression of carcinomas, similar to the decrease in type $\mathrm{V}$ collagen found in our study, is described in the literature. ${ }^{14-16}$ Another question that could easily be addressed by the current study is the correlation between low type $\mathrm{V}$ collagen, low desmoplastic stroma, and decreased blood vessel density; low type V collagen and probably a non-extensive desmoplastic stroma reaction are related to decreased microvessel density and thus to hypoxia and decreased nutrient flow. Thus, the decreased tumor expression of type $\mathrm{V}$ collagen may be more of a primary event, and decreased apoptosis may be more of a secondary event. Regardless of the mechanism, staining of the tumor for type $\mathrm{V}$ collagen and apoptosis provides important information about chemical carcinogenesis in the mouse lung.

We conclude that these data represent a good starting point for the demonstration of the correlation between type $\mathrm{V}$ collagen and apoptosis. Further experimental studies using electron microscopic observations of interactions between type $\mathrm{V}$ collagen and cells displaying apoptotic features, detailed gene expression analysis, or other assays of apoptosis will be necessary.

\section{ACKNOWLEDGEMENTS}

We are grateful to the biologists Sandra de Morais Fernezlian and Esmeralda Eher from the Immunohistochemistry Laboratory of the Department of Pathology, Faculdade de Medicina da Universidade de São Paulo, for technical assistance. 
This study was supported by the following Brazilian agencies: the National Council for Scientific and Technological Development [CNPq]; Foundation for the
Support of Research of the State of São Paulo [FAPESP]; and the Laboratories for Medical Research [LIMs], Hospital das Clinicas, University of São Paulo Medical School.

\section{REFERENCES}

1. Schrump D, Altorki N, Henschke C, Carter D, Turrisi A, Gutierrez M. Non-small cell lung cancer. In: De Vita V. Hellman S. Rosenberg S. editors. Cancer: principles and practice of oncology. 7th ed. Philadelphia: Lippincott Williams and Wilkins; 2005. p. 753-54.

2. Bernardi FD, Capelozzi VL, Takagaki T, Younes R, Saldiva PH. Usefulness of morphometric evaluation of histopathological slides is useful in predicting long-term outcome of patients with squamous cell carcinoma of the lung. A preliminary report. Chest. 1995;107:614-20.

3. Bernardi FDC, Antonângelo L, Beyruti R, Takagaki T, Saldiva PHN, Capelozzi VL. Clinical, pathological and biological markers of prognosis in surgically resected squamous cell carcinoma of the lung. Mod. Pathol. 1997; 10:992-1000

4. Carvalho HA, Takagaki TY, Saldiva PHN, Capelozzi VL. Stereological estimates of the nuclear/cytoplasmic ratio and star volume on fibreoptic biopsies are of prognostic value for survival in a preliminary study of advanced squamous cell carcinoma of the lung. Histopathol. 1997;31:420-29.

5. Antonangelo L, Bernardi FDC, Capelozzi VL, Takagaki T, Younes $\mathrm{R}$, Yagi N, et al. Morphometric evaluation of argyrophilic nucleolar organizer region (AgNOR) is useful in predicting long-term survival in squamous cell carcinoma of the lung. Chest. 1997;111: 110-4.

6. Rodrigues OR, Antonângelo L, Franco Filho EC, Capelozzi VL, Saldiva PHN. Prognostic significance of argyrophilic nucleolar organizer region (AgNOR) staining in mediastinal lymph nodes metastasis and ressected non-small cell lung cancer. Japan. J. Clin. Oncol. 1997;27:298-304.

7. Minamoto H, Antonângelo L, Silva AGP, Gallo CP, Andrade e Silva FB, Fenezelian S, et al. Different cell and microenvironment profiles in metastatic and non-metastatic non-small cell lung carcinomas. Histopathol. 2003;43:427-43.

8. Matheus RS, Bernardi FD, Gallo CP, Silva AGP, Rodrigues OR, Capelozzi M, et al. Nuclear Markers (Star Volume. Mitotic Index. AgNOR and Ki-67) of the Primary Tumor and Its Metastasis in NonSmall Cell Lung Carcinomas. Pathol. Res. Pract. 2004;200:13-23.

9. Saito DM, Franco MR, Parra ER, Ab'saber AM, Farhat C, Eher E, et al. Cell cycle regulator in primary lung adenocarcinoma and its haematogenous metastases. Histopathol. 2007;50:525-7.

10. Parra ER, Park J, Rizzardi F, Takagaki T, Saito DMS, Rodrigues OR, et al Prognostic indices expression of cyclin-d1, c-erbB-2 and VEGF: metastases vs corresponding primary cancers and metastatic vs nonmetastatic adenocarcinomas. Histol. Histopathol. 2008;23: 987-93.

11. Capelozzi VL. Role of immunohistochemistry in the diagnosis of lung cancer. J Bras Pneumol. 2009;35:375-82.
12. Satomi E, Teodoro WR, Parra ER, Fernandes TD, Velosa AP, Capelozzi VL, Yoshinari NH. Changes in histoanatomical distribution of types I, III and V collagen promote adaptative remodeling in posterior tibial tendon rupture. Clinics. 2008;63:9-14.

13. Aznavoorian S, Murphy NA, Stetler-stevenson WG, Liotta LA. Molecular aspects of tumor cell invasion and metastasis. Cancer (Phila.). 1993;71:1368-83.

14. Pinto CA, Carvalho PEO, Antonangelo L, Garippo A, da Silva AGP, Soares F, et al. Morphometric evaluation of tumor matrix metalloproteinase 9 predicts survival after surgical resection of adenocarcinoma of the lung. Clin. Cancer Res. 2003;9:3098-104.

15. Liotta LA, Rao CN, Barsky H. Tumor invasion and the extracellular matrix. Lab. Investig. 1983;49:636-49.

16. Demarchi LMM, Reios MM, Palomino SAP, Farhat C, Takagaki TY, Beiruti R, et al. Prognostic Values of Stroma Proportion and PCNA, K67 and p53 Proteins in Patients with Resected Adenocarcinoma of the Lung. Mod. Pathol. 2000;13:511-20.

17. Mayne R, Burgeson R. Structure and function of collagen types. In: Ulecham R (Ed) Biology of Extracellular Matrix. 20th ed. Academic Press. London. 1993. p 1-37.

18. Mares DC, Heidler KM, Smith Jr GN, Cummings OW, Harris ER, Foresman $\mathrm{BH}$, et al. Type $\mathrm{V}$ collagen modulates alloantigen-induced pathology and immunology in the lung. Am. J. Respir. Cell Mol. Biol. 2000;23:62-70.

19. Linsenmayer TF, Fitch JM, Birk DE. Heterotypic collagen fibrils and stabilizing collagens: Controlling elements in corneal morphogenesis. Ann. N.Y. Acad. Sci. 1990; 580:143-60.

20. Luparello C, Sirchia R. Type V collagen regulates the expression of apoptotic and stress response genes by breast cancer cells. J. Cell Physiol. 2005;202:411-21

21. Minafra S, Morello V, Glorioso F, La Fiura AM, Tomasino RM, Feo S, et al. A new line (8701-BC) from primary ductal infiltrating carcinoma of human breast. Brit J Cancer. 1989;60:185-92.

22. Minafra S, Luparello C, Pucci-Minafra I, Sobel ME, Garbisa S. Adhesion of 8701-BC breast cancer cells to type $\mathrm{V}$ collagen and $67-\mathrm{kD}$ receptor. J. Cell Sci. 1992;102:323-8.

23. Reymão MSF, Cury PM, Lichtenfels AJ, Lemos M, Battlehner CN, Conceição GM, et al. Urban air pollution enhances the formation of urethane-induced lung tumors in mice. Environ. Res. 1997;74:150-8. 
24. Cury PM, Lichtenfels AJFC, Reymão MSF, Conceição GMS, Capelozzi VL, Saldiva PHN. Urban levels of air pollution modifies the progression of urethane-induced lung tumours in mice. Pathol. Res. Pract. 2000;196:627-33.

25. Kauffman SL, Alexander L, Sass L. Histologic and ultrastructural features of Clara Cell adenoma of the mouse lung. Lab Invest. 1979;40:708-16.

26. Ward JM, Singh G, Katyal S, Anderson LM, Kovatch RM. Immunocytochemical localization of the surfactant apoprotein and Clara cell antigen in chemically induced and naturally occurring pulmonary neoplasm of mice. Am J Pathol. 1985;118:493-9

27. Gavrieli Y, Sherman Y, Bem-Sasson SA. Identification of programmed cell death in situ via specific labeling of nuclear DNA fragmentation. J. Cell Biol. 1992;119:493-501.

28. Wijsman JH, Jonker RR, Keijzer R. A new method to detect apoptosis in paraffin sections: in situ end labeling of fragmented DNA. J Histochem Cytochem. 1993;41:7-12.

29. Miller EJ, Rhodes RK. Preparation and characterization of the different types of collagen. Methods Enzymol. 1982;82:33-64.

30. Lane HD. Antibodies - A laboratory manual. ed. Cold Spring Harbor Laboratory. 1988. p 56-81.

31. Weibel ER. Morphometry: stereological theory and practical methods. In: Gil J (Ed). Models of Lung Disease-Microscopy and Structural Methods. New York. Marcel Dekker. 1990. p. 199-247.

32. Bateman JF, Lamandè SR, Ramshaw JAM. Collagen superfamily. In: Comper WD. editor. Extracellular matrix volume 2 molecular components and interaction. Amsterdam: Harwood Acad. Public. 1996. p 22-67.

33. Teodoro WR, Velosa AP, Witzel SS, Garippo AL, Farhat C, Parra ER, et al. Architectural remodelling in lungs of rabbits induced by type $\mathrm{V}$ collagen immunization: a preliminary morphologic model to study diffuse connective tissue diseases. Pathol Res Pract. 2004;200:681-91.

34. Velosa AP, Teodoro WR, de Oliveira CC, Dos Santos Filho A, Moutinho RF, Santos AG, et al. Collagen V nasal tolerance in experimental model of systemic sclerosis. Arch Dermatol Res. 2007;299:177-89.

35. Ogido LT, Teodoro WR, Velosa AP, de Oliveira CC, Parra ER, Capelozzi VL, et al. Abnormal collagen deposition in synovia after collagen type V immunization in rabbits. Histol Histopathol. 2008;23:263-9.
36. Bezerra MC, Teodoro WR, de Oliveira CC, Velosa AP, Ogido LT, Gauditano G, et al. Scleroderma-like remodeling induced by type V collagen. Arch Dermatol Res. 2006;298: 51-7.

37. Parra ER, Teodoro WR, Velosa AP, de Oliveira CC, Yoshinari NH, Capelozzi VL. Interstitial and vascular type V collagen morphologic disorganization in usual interstitial pneumonia. J Histochem Cytochem. 2006;54:1315-25.

38. Parra ER, Kairalla RA, de Carvalho CR, Capelozzi VL. Abnormal deposition of collagen/elastic vascular fibres and prognostic significance in idiopathic interstitial pneumonias. Thorax. 2007;62:428-37.

39. Takai KK, Hattori S, Irie S. Type V collagen distribution in liver is reconstructed in coculture system of hepatocytes and stellate cells; the possible functions of type $\mathrm{V}$ collagen in liver under normal and pathological conditions. Cell Struct Funct. 2001;26:289-302.

40. Chernousev MA, Stahl RC, Carey DJ. Schwann cell type V collagen inhibits axonal outgrowth and promotes Schwann cell migration via distinct adhesive activities of the collagen and noncollagen domains. J Neurosci. 2001;21:6125-35.

41. Grotendorst GR, Seppã HE, Kleimanman HK, Martin GR. Attachment of smooth muscle cells to collagen and their migration toward plateletderived growth factor. Proc Natl Acad Sci. USA 1981;78:3669-72.

42. Ruggiero F, Champliaud MF, Garrone R, Aumailley M. Interactions between cells and collagen $\mathrm{V}$ molecules or single chains involve distinct mechanisms. Exp Cell Res. 1994; 210:215-23.

43. Parekh TV, Wang XW, Makri-Werzen DM, Greenspan DS, Newman MJ. Type V collagen is an epithelial cell cycle inhibitor that is induced by and mimics the effects of transforming growth factor $\alpha 1$. Cell Growth Differe. 1998;9:423-33.

44. Bharat A, Fields RC, Steward N, Trulock EP, Patterson GA, Mohanakumar T. CD4+25+ regulatory T cells limit Th1-autoimmunity by inducing IL-10 producing $\mathrm{T}$ cells following human lung transplantation. Am. J. Transplantation. 2006;6:1799-808.

45. Hofmann K. The modular nature of the apoptotic signaling proteins Cell Mol Life Sci. 1999;55:1113-8.

46. Sgonc R. The vascular perspective of systemic sclerosis: of chickens, mice and men. Int Arch Allergy Immunol. 1999;120:169-76. 